\section{Endoscopic repair of a massive postoperative pancreatic juice leak through the bile duct stump due to pancreatobiliary maljunction}
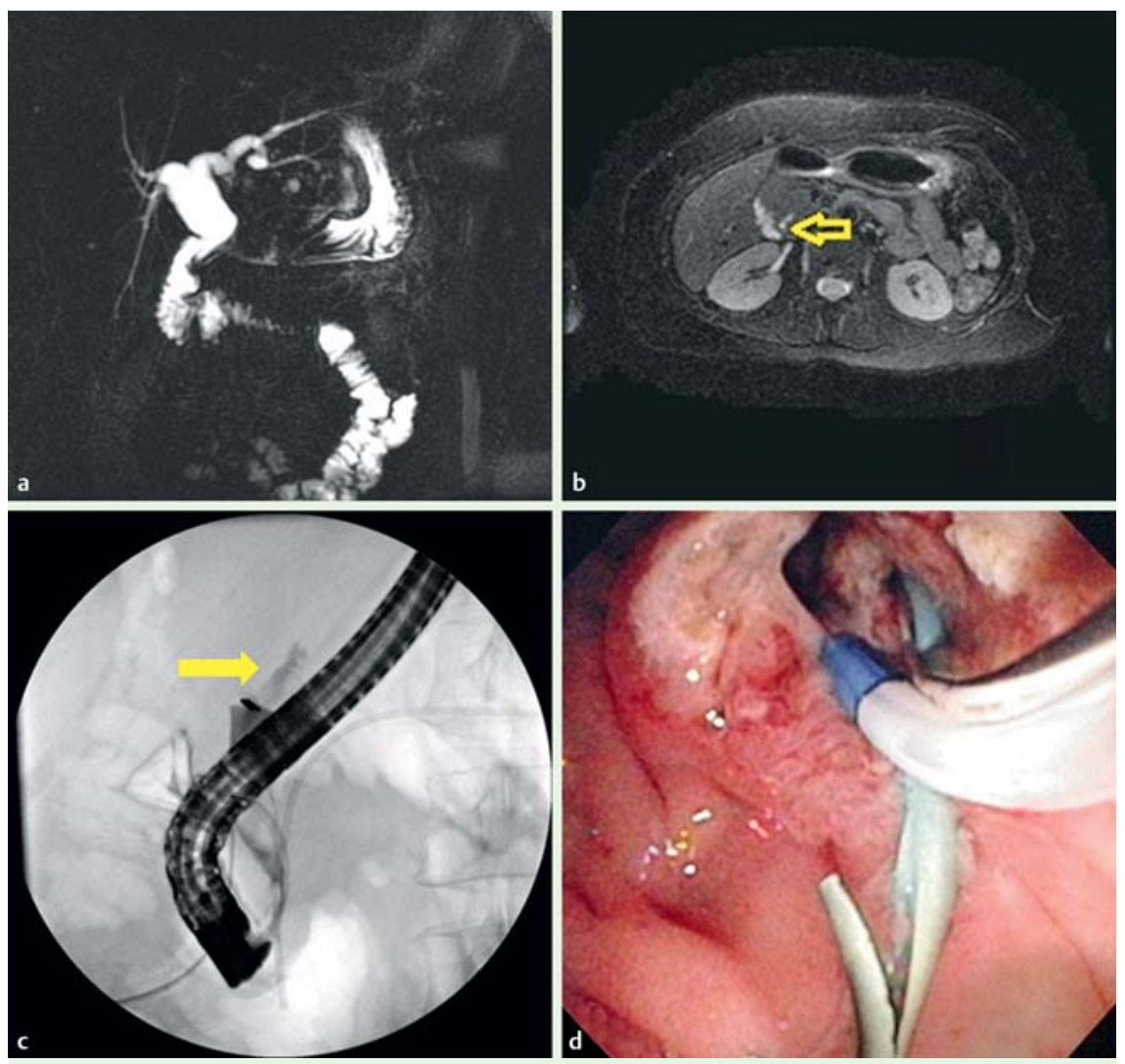

Fig. 1 a Radiographic image in a patient with a choledochal cyst, Todani type IVA, showing massive dilatation of the common bile duct (CBD) and saccular dilatation of the intrahepatic ducts. b Computed tomography (CT) scan showing an obvious pancreaticobiliary maljunction (PBM); Komi type Ilb) and an acute angle of insertion of the pancreatic duct into the CBD (open yellow arrow). c Endoscopic retrograde cholangiopan-

A 55-year-old woman underwent suprapancreatic resection of a large choledochal cyst, Todani type IVA, associated with pancreatobiliary maljunction (PBMJ), Komi type IIb [1] ( Fig. 1 a, b and $\bullet$ Fig. 2). The pancreatic parenchyma was not incised or cauterized during surgery.

On the first postoperative day, a large amount $(500-600 \mathrm{~mL})$ of an amylase and lipase-rich secretion was noted to be draining out of the Jackson-Pratt drain. An endoscopic retrograde cholangiopancreatography (ERCP) was performed to evaluate the pancreatobiliary anatomy,

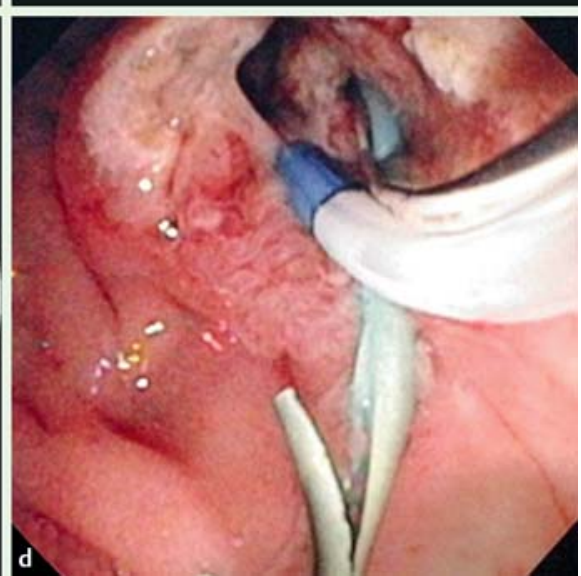

creatography (ERCP) clearly showing the PBM] and ongoing "pancreatobiliary" leak, as demonstrated by contrast extravasation (solid yellow arrow). $\mathbf{d}$ Endoscopic appearance after biliary sphincterotomy had been performed showing the opening of the pancreatic duct with a stent in situ and the wide opening to the common bile duct (shown by the sphincterotome tip).

which confirmed the PBMJ. Pancreatic duct sphincterotomy was performed and was followed by insertion of a 7-Fr pancreatic plastic stent. Despite this therapy, there was persistent drainage of pancreatic enzyme-rich juice $(500 \mathrm{~mL})$ through the Jackson-Pratt drain.

A repeat ERCP clearly demonstrated the PBMJ and evidence of ongoing leakage $(\bullet$ Fig.1 c). Therefore, a biliary sphincterotomy was performed. Close endoscopic inspection after the sphincterotomy clearly demonstrated the opening of the pancreatic duct, which had been previously stented, and the wide entrance to the common bile duct ( $\bullet$ Fig. 1 d). With no sphincters to cause resistance, the pancreatic juice was able to flow freely through the common channel into the duodenum, without regurgitating through the PBMJ into the bile duct stump, and drainage of pancreatic juice through the Jackson-Pratt drain stopped within 24 hours.

Postoperative pancreatic juice leaks are not uncommon after pancreatic surgery. These usually occur because of pancreatic parenchymal injury, transmural burn, dissection or transection of the pancreatic duct, or from the pancreatojejunal anastomosis. However, pancreatic juice leaks in the absence of injury to the pancreas or the pancreatic duct are extremely rare. Our case is interesting as it shows that a "pancreatic duct" leak can occur through the bile duct stump in the absence of injury to the pancreatic duct or parenchyma, as a result of a PBMJ.

Endoscopic therapy consisted of sphincterotomy of both the pancreatic and bile duct sphincters, along with pancreatic duct stenting. Once the bile duct sphincter had been incised, the leak resolved within 2 weeks. Knowledge of this anatomical variant based on the Komi classification is important when dealing with suspected postoperative injury to the pancreas and/ or pancreatic duct $[1,2]$.

\section{Endoscopy_UCTN_Code_TTT_1AR_2AI}

\section{Competing interests: None}

\section{Claudia Diaz-Tobar ${ }^{1}$, Awad El-Ashry², John D. Christein ${ }^{2}$, Klaus Mönkemüller ${ }^{1}$}

${ }^{1}$ Basil I. Hirschowitz Endoscopic Center of Excellence, Division of Gastroenterology and Hepatology, University of Alabama at Birmingham, Alabama, USA

2 Department of Surgery, University of Alabama at Birmingham, Alabama, USA

\section{Acknowledgment \\ $\nabla$}

Dr. Diaz-Tobar performed this work during her "Boston Scientific Visiting Fellowship" at the Basil I. Hirschowitz Center of Endoscopic Excellence, Division of Gastroenterology, University of Alabama at Birmingham, USA. Mr. Jose Diaz designed and created the graphic. 


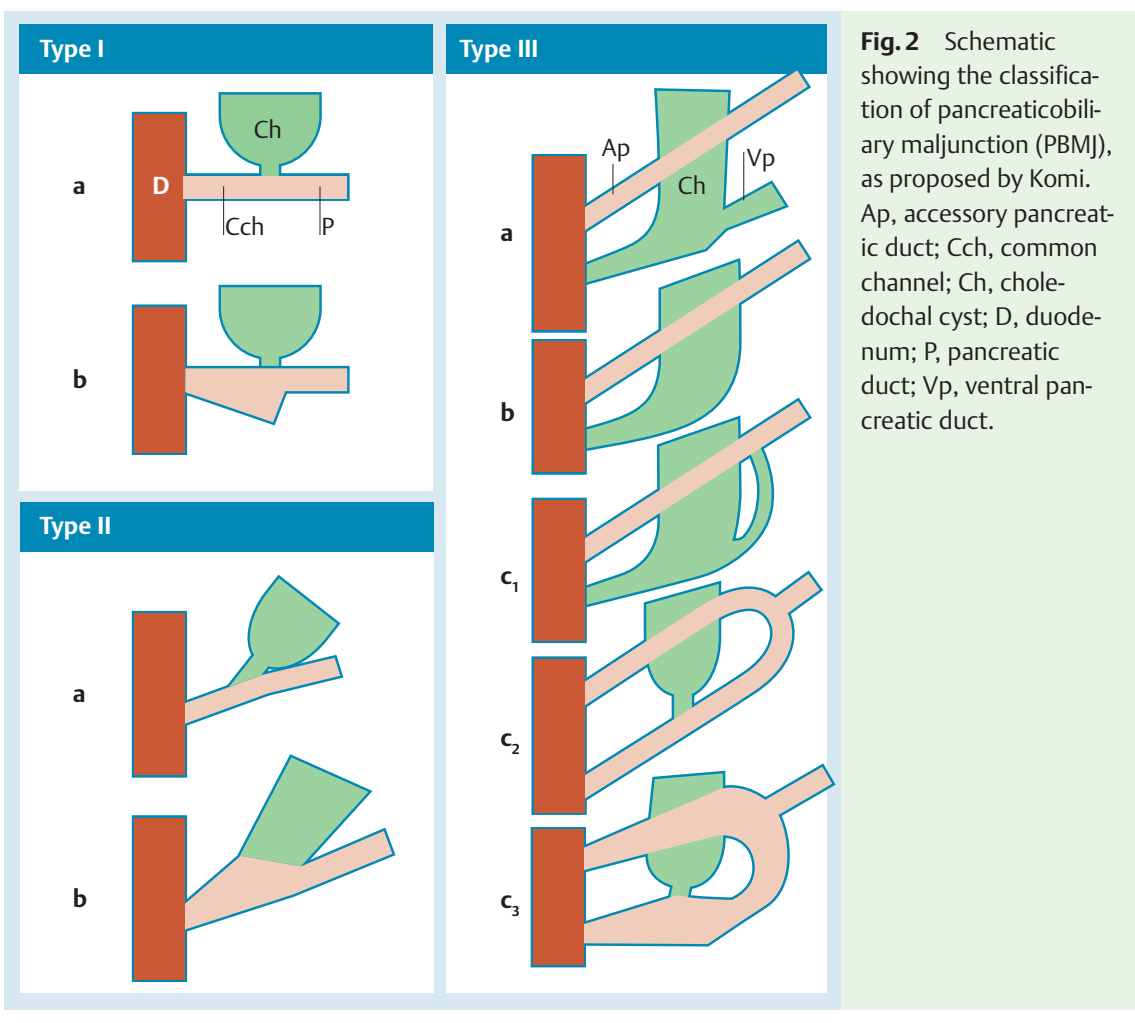

\section{References}

1 Komi $N$, Takehara H, Kunitomo K et al. Does the type of anomalous arrangement of pancreaticobiliary ducts influence the surgery and prognosis of choledochal cyst? J Pediat Surg 1992; 27: $728-731$

2 Lee HK, Park SJ, Yi BH et al. Imaging features of adult choledocal cysts: a pictorial review. K J Radiol 2009; 10: $71-80$

\section{Bibliography}

Dol http://dx.doi.org/

10.1055/s-0034-1365095

Endoscopy 2014; 46: E165-E166

(c) Georg Thieme Verlag KG

Stuttgart · New York

ISSN 0013-726X

\section{Corresponding author}

\section{Klaus Mönkemüller, MD, PhD}

Division of Gastroenterology and Hepatology

Basil I. Hirschowitz Endoscopic Center

of Excellence

Endoscopy Unit, JT 664

619 19th Street S

Birmingham

AL 35249

USA

Fax: +1-205-934-1537

klaus1@uab.edu 